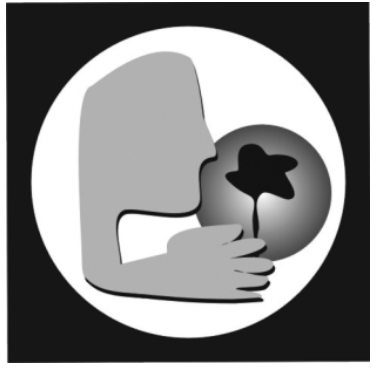

Sustentabilidade e $\mathrm{m}$ Debate

Recebido em 18.12.2009

Aceito em 22.04.2010

\section{Fatores Político-Econômicos} do Desmatamento na Amazônia Oriental

\author{
Jefferson Lorencini Gazoni ${ }^{1}$, José Aroudo Mota ${ }^{2}$ \\ ${ }^{1}$ Mestre e doutorando em Desenvolvimento Sustentável (CDS/UnB). \\ Pesquisador (PNPD) da Diretoria de Estudos Regionais e Urbanos \\ (DIRUR) do Instituto de Pesquisa Econômica Aplicada (IPEA). \\ Endereço eletrônico: jefferson.gazoni@ipea.gov.br.
}

${ }^{2}$ Doutor em Desenvolvimento Sustentável (CDS/UnB). Coordenador de Meio Ambiente e Desenvolvimento Sustentável da Diretoria de Estudos Regionais e Urbanos (DIRUR) do Instituto de Pesquisa Econômica Aplicada (IPEA) e Coordenador do Fórum Ipea de Mudanças Climáticas - Endereço eletrônico: jamota@ipea.gov.br.
Palavras-Chave:

Desenvolvimento sustentável

Política ambiental

Agronegócio
Key-words:

Sustainable development

Environmental policy

Agribusinessm

\section{RESUMO}

Este estudo investigou as relações entre aspectos político-econômicos e o desmatamento na Amazônia Oriental, com o propósito de avaliar os principais fatores primários que contribuíram para o desmatamento recente da floresta regional ou para a sua proteção. Metodologicamente, utilizou-se de regressão múltipla com dados coletados por meio de uma série de corte (cross-section) das informações dos municípios localizados na porção oriental do bioma Amazônia, dados desses válidos para o período 2007/2008. Os resultados evidenciaram que os principais fatores associados em primeiro nível às taxas de desmatamento na região são a área agropecuária, as produções de madeira e carvão vegetal, a produção extrativista não-madeireira, a distância ao escritório regional do Ibama mais próximo, as áreas protegidas e o estoque florestal. Neste sentido, os estudos sobre o desmatamento da Amazônia devem ampliar a atenção quanto às atividades econômicas que podem proteger ao invés de destruir a floresta.

\section{ABSTRACT}

This paper studies the relationships between political and productive activities and the deforestation in Eastern Amazon biome with the purpose of evaluating the main factors of the latest regional forest's deforestation. Methodologically, it used a multiple regression of the districts in Eastern Amazon from 2007 to 2008 . The results evidenced that the primary driving forces of the recent deforestation in region are the bovine cattle breeding and agriculture, the wooden and charcoal production, the extraction of non timber forest products, the distance for National Environmental Offices in region, the protected areas and the forest stock. In this context, the researches on deforestation have to focuses on the economic activities that can protect de forest against deforestation. 


\section{Fatores político-econômicos do desmatamento na Amazônia Oriental}

\section{Introdução}

Os impactos das atividades humanas sobre o meio ambiente ganham cada vez maior atenção, principalmente devido à perda de bens e serviços ambientais que afetam o bem-estar das sociedades. Neste contexto, a insatisfação gerada pelo uso indiscriminado dos recursos naturais da Amazônia é amparada pelo entendimento de que, no atual modelo político-econômico, baseado na noção de livre mercado, os benefícios geralmente são menores que os custos socioambientais. São diversos os impactos das ações antrópicas na Amazônia, mas, sem dúvida, o desmatamento é o mais devastador.

$\mathrm{O}$ desmatamento pode ser entendido como um corte raso da floresta, diferente do desflorestamento, que envolve ainda a fragmentação e a degradação (Pasquis e Bouamrane, 2002). Ele tem levado à perda de serviços ambientais valiosos tanto para as sociedades como para os ecossistemas, incluindo os de manutenção da biodiversidade, da ciclagem da água e dos estoques de carbono. Deve-se atentar que a floresta atua no sequiestro e na formação de um megaestoque de carbono (Pfaff, 1999; Fearnside, 1997), que vem sendo liberado à atmosfera por meio do desmatamento e das queimadas (Nogueira et al., 2007).

As florestas tropicais ocupam cerca de $7 \%$ da superfície terrestre e abrigam mais de $50 \%$ das espécies conhecidas no planeta (Ewers e Laurance, 2006). A Amazônia brasileira contém cerca de $40 \%$ destas florestas (Kirby et al., 2006; Barbier, 2001). É nesse contexto que o desmatamento tem potencial para influenciar o clima regional e global e para contribuir para a redução da biodiversidade em outros lugares (Sawyer, 2007; Malhi et al., 2008; Portela e Rademacher, 2001). Em nível local podem surgir outros graves impactos, tais como o assoreamento de rios, córregos e lagoas (Cataneo, 2001) e a degradação dos solos (Angelsen e Kaimowitz, 1999), com consequientes prejuízos econômicos para as populações dependentes da coleta ou da agricultura em pequena escala.

Estudos sugeriram (Steward, 2007; Soares Filho et al., 2005; Pimm, 1998) que vastas áreas florestais da Amazônia, principalmente em seu trecho ori- ental, vêm sendo convertidas para uso da agricultura, da pecuária, da extração indiscriminada de madeira, entre outras atividades produtivas, resultando em danos, muitas vezes, irreparáveis. Por outro lado, demandas pela redução das desigualdades regionais e pela melhoria das condições de vida das populações amazônicas pressionam pela provisão de infraestruturas e serviços essenciais ao bem-estar dessas comunidades. Além disso, demandas nacionais e internacionais pressionam a região no sentido da produção de bens, principalmente os primários, para o atendimento de suas crescentes necessidades. É neste contexto que se ampliam as discussões em busca de alternativas para o uso e a exploração sustentável da floresta, de forma a garantir as necessidades das populações locais, as demandas econômicas e a proteção dos recursos naturais. Por esses aspectos, é urgente entender as relações político-econômicas que envolvem o desmatamento na Amazônia Oriental, tanto para ampliar os conhecimentos sobre o tema como para correlacionar aspectos identificados por esta pesquisa aos já apresentados na literatura pertinente.

Este estudo partiu do seguinte questionamento: quais são as relações dos aspectos políticoinstitucionais e atividades produtivas regionais com o desmatamento recente do bioma Amazônia em sua porção territorial oriental, ou seja, nos municípios contidos no bioma Amazônia e localizados nos estados do Amapá, Pará, Mato Grosso, Tocantins e Maranhão. O objetivo é avaliar os fatores primários que acarretam as taxas de desmatamento. Metodologicamente, utilizou-se da técnica de regressão linear múltipla por mínimos quadrados ordinários em uma série de corte (cross-section) das informações municipais no período de agosto de 2007 a julho de 2008. Assim, foi estimado um modelo estatístico capaz de representar as taxas anuais de desmatamento municipal em função de atividades produtivas, de aspectos institucionais e de políticas públicas.

O texto está estruturado em quatro seções principais. Inicialmente, discute a sustentabilidade socioambiental frente ao processo de alteração do uso e da cobertura do solo. Em seguida, apresenta uma revisão da literatura acerca das causas, efeitos e di- 


\section{Sustentabilidade em Debate}

nâmicas do desmatamento na Amazônia. Apresentase a metodologia da pesquisa e, ao final, avalia-se a influência dos fatores sobre as taxas anuais de desmatamento, discutidos sob o enfoque da sustentabilidade.

\section{Desenvolvimento e Sustentabilidade: Reflexões Sobre o Uso e a Cobertura do Solo}

A percepção da necessidade de se alcançar modelos sustentáveis de desenvolvimento que integrem crescimento econômico, justiça social e proteção dos recursos naturais já pode ser considerada consensual. O desenvolvimento sustentável, entendido como um desenvolvimento que deve atender às necessidades das presentes gerações sem comprometer a possibilidade das gerações futuras satisfazerem as suas próprias necessidades é uma opção premente. A sustentabilidade é um critério fundamental para estimular as responsabilidades e para se reconsiderar aspectos relacionados com a equiidade e a justiça social, tanto intra-geracionais como inter-geracionais. Apesar de ser um conceito de fácil entendimento e aceitação, a busca pela sustentabilidade enfrenta grandes desafios.

A imprevisibilidade dos sistemas naturais é um importante fator que deve ser considerado nas pesquisas e políticas em relação às questões socioambientais. Trata-se de atentar para o funcionamento do sistema planetário. É um sistema singular, cujo componente essencial é a biosfera, na qual as atividades humanas atuais são capazes de promover profundas transformações que se propagam pelo sistema global, em uma escala complexa, interativa e acelerada (Steffen et al., 2004). Três dimensões em especial exigem atenção: a complexidade, a interdisciplinaridade e a temporalidade. $\mathrm{O}$ desenvolvimento sustentável implica na sustentação de bens e serviços ambientais em qualidade tal que permita o seu aproveitamento pelas próximas gerações. Assim, deve levar em consideração que o tempo geológico, o tempo biológico e o tempo cronológico têm diferentes escalas. Ou seja, é necessário considerar estas diferentes escalas temporais ao se desenvolver qualquer proposta de uso sustentável dos recursos.
Os sistemas socioambientais são complexos, ou seja, são formados por uma grande quantidade de elementos em interação dinâmica e não-linear. Além disso, os seus elementos estão, geralmente, organizados em níveis hierárquicos internos, ou seja, os efeitos das interações entre os elementos não provoca variações constantes no sistema, cujo funcionamento está relacionado com a combinação de suas retroações. A intensidade, direção e combinação das retroações provocadas por uma transformação ou uma ação repercutem sobre os sistemas de formas diversas. Estas variações podem ocorrer porque o sistema achase inicialmente em um estado instável e tende para um estado estável (DeRosnay, 1975). Diversas pesquisas destacaram que estas mudanças de estados dos ecossistemas têm sido interrompidas por rápidas e drásticas mudanças para novos e contrastantes estados (Scheffer et al., 2001). Ou seja, a superação de determinados limites de sustentação da estrutura do sistema (resiliência) promove a ruptura e conseqüente reorganização do ecossistema em um novo estado de equilíbrio alternativo, gerando muitas vezes, danos socioambientais.

Esses fenômenos freqüentemente surpreenderam as civilizações no passado, levando muitas ao colapso (Diamond, 2006). Atualmente, eventos ambientais, extremos ou resultantes de acúmulos nãopercebidos, têm afetado a vida de milhões de pessoas em todo o mundo. Esses sinais não devem ser ignorados, como no passado. A compreensão de que esses são processos complexos e dinâmicos exige, cada vez mais, ética e responsabilidade nas tomadas de decisão. A utilização da terra para fornecimento de alimentos, madeiras, recursos minerais, entre outros, é uma das características das sociedades humanas. Há uma grande quantidade de efeitos indesejados desses processos de ocupação e uso. Neste sentido, atualmente a decisão da utilização dos recursos do solo e sua cobertura envolvem trocas (trade-offs) entre a satisfação imediata das necessidades e dos desejos humanos e esses efeitos indesejados, baseadas nos valores sociais e no conhecimento ecológico.

O Diagrama 1 concebe como as necessidades e os desejos humanos são traduzidos em alterações no uso e na cobertura do solo. As setas no diagrama representam fluxos de informações, distinto dos fluxos 
de matéria e energia, que podem ocorrer em sentido oposto em alguns casos. O diagrama está estruturado em três níveis de escala: local, regional e global; dividido em três colunas. À direita, evidenciam-se as forças básicas do uso do solo, representadas pela população e pelas aspirações humanas. Estas forças motrizes são adaptadas pelos sistemas de decisão, na coluna central. Na parte direita, representam-se alguns elementos do sistema natural e o processo de mudanças causadas pelos sistemas de decisão.

As aspirações individuais e coletivas são influenciadas pela cultura, pelo clima local e pelos aspectos geográficos. As condições ambientais locais, como aspectos climáticos (temperatura, regime de chuvas) e geográficos (localização, altitude e relevo), e o contexto sociocultural afeta a percepção individual sobre a importância relativa de seus desejos e necessidades (DeFries et al., 2004). Esses desejos e necessidades são influenciados externamente por retroações, principalmente do microssistema de decisão que, por sua vez, é influenciado por aspectos atmosféricos e por mudanças nos ciclos globais.
O subsistema de micro-decisões representa as menores unidades de tomadas de decisão cujas ações afetam diretamente ou indiretamente o uso e a cobertura do solo. Essas decisões são apenas uma parte do conjunto de decisões. As causas das mudanças no uso do solo podem não ser exclusivamente decisões do microssistema de decisão, pois elas podem vir do subsistema de macro-decisões (Walker et al., 2002). Por exemplo, uma política regional ou nacional pode ocasionar migração e substituição das formas tradicionais de uso e ocupação na região de destino.

O subsistema de macro-decisões descreve duas funções básicas: coordenação das ações das unidades de decisão em nível inferior e comunicação com os demais tomadores de decisão no mesmo nível, por meio dos mecanismos institucionais da economia política global. As interações entre a arena econômica (mercados), a arena política (instituições políticas) e a arena social (estruturas sociais e culturais), cada uma representando um mecanismo diferente para a agregação das aspirações humanas em nível local e

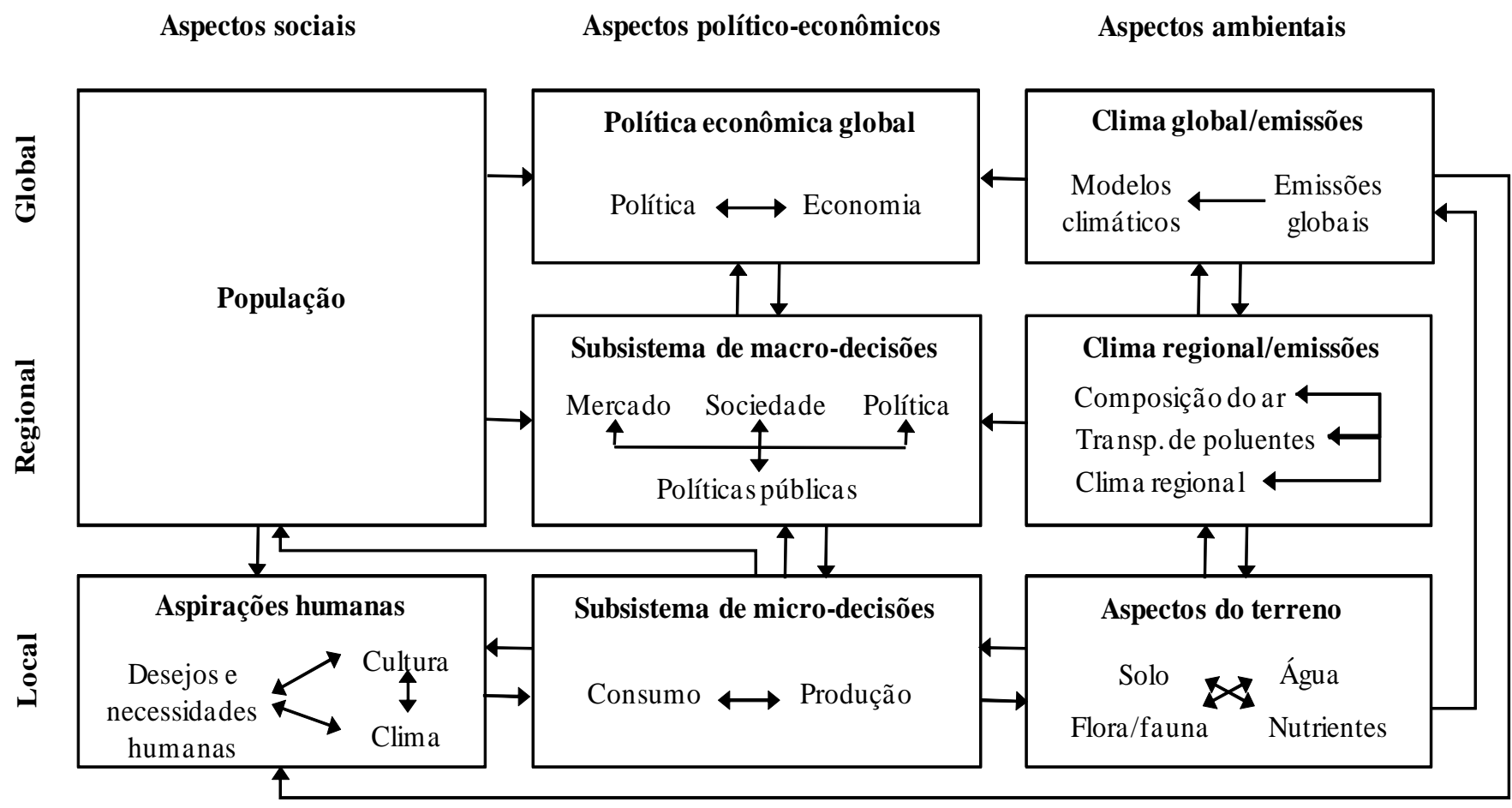

Diagrama 1: Interações do uso e da cobertura do solo - uma referência para estudos interdisciplinares.

Fonte: ampliado a partir de Rayner et al. (1994); Bürgi; Hersperger e Schneeberger (2004) e Turner; Lambin e Reenberg (2007). 


\section{Sustentabilidade em Debate}

as políticas públicas vigentes, resultam em alterações das existentes e/ou novas políticas públicas.

A unidade população envolve fatores imprescindíveis para a compreensão dos impactos cumulativos sociais e ambientais provenientes das decisões em níveis inferiores. As principais entradas da unidade população são provenientes do subsistema de micro-decisões que, em muitas sociedades, equivale à unidade familiar (Rayner et al., 1994). Informações sobre o tamanho e outras características da população subsidiam o entendimento de outros subsistemas.

A política econômica global influencia os subsistemas de macro e micro-decisões, ou seja, em níveis local, regional ou nacional. O clima e a composição atmosférica regional é uma unidade formada por três subgrupos e executa duas funções principais: 1) transferir informações dos modelos gerais de circulação atmosférica, associada com os aspectos do solo e sua cobertura, para a compreensão do microclima regional; e 2) descrever a composição e o transporte dos poluentes no ar que decorrem das alterações de uso e cobertura do solo.

Os aspectos do solo e sua cobertura descrevem os campos de conhecimentos suficientes para avaliar a viabilidade e a sustentabilidade das alterações de uso e cobertura do solo. As principais influências externas à unidade são provenientes do subsistema de micro-decisões e da unidade da atmosfera e clima regional. Informações sobre sistema de transportes, moradia, agricultura, incluindo práticas de produção, como o uso de inseticidas e fertilizantes, entre outras, são fornecidas pelo subsistema de micro-decisões.

As repercussões das alterações da superfície são profundas para o funcionamento dos ecossistemas. Podem-se citar: 1) alterações do microclima regional; 2) alteração do clima global; 3) perda de biodiversidade; 4) degradação dos solos; 5) aumento da vulnerabilidade de cidades e pessoas em relação a alterações ambientais; e, entre outros, 6) alteração do funcionamento do sistema terrestre.

As forças motrizes das mudanças de uso e cobertura do solo são complexas, interdependentes e se relacionam em diversos níveis espaciais e temporais (Bürgi; Hersperger e Schneeberger, 2004). As dinâmicas são geralmente causadas por múltiplos fatores. Essas forças variam de acordo com a ocasião. Para
Lambin, Geist e Lepers (2003), essas forças causais podem ser agrupadas em: variabilidade natural, fatores econômicos e tecnológicos, fatores demográficos, fatores institucionais, fatores culturais e globalização. Os autores ainda destacaram o que denominaram as cinco maiores causas das alterações do uso e da cobertura do solo: 1) a escassez de recursos aliada ao aumento de demanda; 2) mudanças de oportunidades geradas pelos mercados; 3 ) intervenções por políticas públicas externas; 4) perda da capacidade de adaptação e aumento de vulnerabilidade e 5) mudanças nas estruturas e organização social no acesso aos recursos. Pode-se sugerir que os aspectos brevemente apresentados aqui têm correspondência com o desmatamento da Amazônia.

\section{O Desmatamento da Amazônia: causas, Efeitos e Dinâmicas}

A área total da Amazônia Internacional é de 6,5 milhões km². Além do Brasil (63,1\%), o Peru (17,0\%), a Bolívia (11,0\%), a Colômbia (5,8\%), o Equador $(2,2 \%)$, a Venezuela $(0,7 \%)$ e a Guiana $(0,2 \%)$ detêm porções deste território, onde predominam dois biomas principais: o Bioma Amazônia, com 3,2 milhões de $\mathrm{km}^{2}$ (cerca de $80 \%$ do total) e o Cerrado, com aproximadamente 1,0 milhão de $\mathrm{km}^{2}$. Formado por uma conjunção de ecossistemas heterogêneos (áreas de terra firme, rios e áreas alagadas), este território abriga a maior floresta tropical do mundo e protege cerca de um terço das espécies existentes no planeta (Albagli, 2001). AAmazônia ainda abriga cerca de 170 povos indígenas, centenas de comunidades remanescentes de quilombos e milhares de outras comunidades locais (MMA, 2006).

No início do século XX, aproximadamente $80 \%$ da área da Amazônia brasileira eram florestadas e as áreas remanescentes cobertas por cerrado e campos. Até a década de 1940 ela pouco se transformou. A maior parte da população regional de cerca de quatro milhões de habitantes residia ao longo das planícies aluviais, onde a terra era mais fértil, devido ao trânsito e deposição de sedimentos provenientes das regiões montantes e ao acesso que dava-se quase exclusivamente por meio fluvial. (Kirby et al., 2006). As primei- 


\section{Fatores político-econômicos do desmatamento na Amazônia Oriental}

ras atividades produtivas nestas planícies foram a pequena agricultura diversificada e a criação de gado bovino (Desfontaines, 1957). Foi a partir de então que políticas públicas iniciaram a promoção da ocupação regional. A Constituição Federal de 1946 indicou e a Lei $n^{\circ} 1.806$, de 6 de janeiro de 1953, criou o Plano de Valorização Econômica da Amazônia, cuja execução foi atribuída à Superintendência do Plano de Valorização Econômica da Amazônia. Mais tarde, esta atribuição foi transferida para a Superintendência do Desenvolvimento da Amazônia (SUDAM) (Tourrand et al., 2007). Apesar dessa intenção do Governo Federal, a ausência de rodovias inviabilizava o acesso a áreas atraentes para brasileiros de outras regiões, dificultando o pleno crescimento regional.

Somente no final da década de 1960, com a inauguração da nova Capital Federal e com a construção da Rodovia Belém-Brasília (BR-010), iniciada em 1958, o processo de ocupação foi acelerado. Durante o governo militar, a política de desenvolvimento, baseada no argumento de que era preciso garantir a posse da Amazônia, promoveu profundas transformações. As principais ações voltadas ao desenvolvimento regional nesse momento foram o início da construção da rodovia Cuiabá - Porto Velho e da Transamazônica (Théry, 2005; Nepstad et al., 2001). Essas rodovias formaram o primeiro eixo de desmatamento regional.

Na segunda metade década de 1980 e no início da década de 1990, políticas de desenvolvimento proveram infra-estruturas e facilidades que criaram condições para a imigração e para os investimentos na região (Börner; Mendoza e Vosti, 2007). As principais propostas para a Amazônia foram a recuperação das rodovias Transamazônica e Cuiabá - Santarém e o asfaltamento da rodovia Manaus - Boa Vista.

Nos últimos anos, a grande maioria das ações e dos investimentos nos eixos de desenvolvimento previstos para a Amazônia Legal ocorreu nos Eixos Madeira-Amazonas e Araguaia-Tocantins por meio da provisão de infra-estruturas de suporte ao escoamento da produção. Os investimentos em agroindústrias e pecuária ocorreram devido à proximidade com as áreas de produção, onde a pequena produção foi substituída pela pecuária e, em seguida, pela produção de grãos (Mello, 2006). Este proces- so gerou a espacialização das populações e das atividades produtivas, marcada por grande heterogeneidade, com distribuição desigual na Amazônia brasileira. Este processo tem resultado na formação de uma área de transição que pode ser identificada junto às fronteiras leste e sudeste da Amazônia, também denominada arco do desmatamento ou arco do povoamento consolidado (Becker, 2005). Além disso, as áreas próximas às capitais estaduais ou aos centros regionais têm promovido grandes alterações em suas áreas de influência (Igliori, 2006).

Para se ter uma idéia da dimensão dessas transformações, em 1950 a população da Amazônia Legal era de somente 3,8 milhões de habitantes. Em 2007, chegou a 23,6 milhões, ou seja, $12,83 \%$ da população nacional (IBGE, 1950; 2007). O comportamento recente do PIB na Amazônia mostra que ela tem crescido a taxas menores que a média nacional, chegando em 2006 a somente 7,76\% do PIB nacional. As maiores economias amazônicas encontram-se nos estados do Pará ( $\mathrm{R}$ \$ 44,37 bilhões), Amazonas ( $\mathrm{R}$ \$ 39,16 bilhões), Mato Grosso (R $\$ 35,28$ bilhões) e Maranhão ( $\mathrm{R} \$ 28,62$ bilhões). O PIB per capita ( $\mathrm{R} \$ 8,37$ mil) cresceu cerca de $1 \%$ ao ano nos últimos anos na região, mantendo-se menor que a média brasileira. Em 1985, o PIB per capita da região era o equivalente a 52,1\% do PIB per capita médio do Brasil. Em 2006 esta proporção foi de $65,9 \%$, sugerindo significativa melhoria (IBGE, 1985; 2006). Todavia, a qualidade de vida da população ainda é insuficiente. O Índice de Desenvolvimento Humano (IDH), que considera indicadores de educação, longevidade e renda de oito dos nove estados da região, é inferior ao IDH nacional, exceção feita ao estado de Mato Grosso $(0,773)$. Por esses aspectos, pode-se questionar o modelo de desenvolvimento adotado historicamente para a Amazônia brasileira, pois, além de não promover a efetiva melhoria da qualidade de vida das populações residentes, ainda promove grandes impactos e graves danos ambientais. Entre esses impactos, o mais evidente é o desmatamento, que já destruiu aproximadamente $15 \%$ da área original (Brasil, 2007), ou seja, 732 mil km² de florestas nativas.

Diversas são as causas apontadas para o desflorestamento na Amazônia brasileira presentes na 


\section{Sustentabilidade em Debate}

literatura nacional e internacional. Entretanto, a grande maioria dos estudos carece de profundidade. Por isso, ainda existem controvérsias sobre os fatores determinísticos do desmatamento regional, principalmente quanto à contribuição específica de cada fator. Os fatores identificados como determinísticos em alguns estudos localizados são apresentados pelo Quadro 1. Podem-se verificar as freqüências com que os fatores aparecem nos resultados dos trabalhos examinados. Os apontados com maior freqüência como determinísticos foram: fatores de transporte e rodovias, a pecuária e a agricultura. Com menores freqüências apareceram as atividades madeireiras, o preço da terra e a população. Citados por apenas um estudo cada, os preços dos produtos agrícolas, o crédito rural e as distâncias às capitais estaduais.

Os resultados de mais de 140 modelos econômicos que analisaram as causas do desflorestamento das florestas tropicais foram sintetizados por Angelsen e Kaimowitz (1999). Esses estudos sugeriram que os fatores que promoviam o desflorestamento até então eram: a provisão de estradas, os preços dos produtos agrícolas, os baixos rendimentos dos trabalhadores, o crescimento populacional, o montante de rendimentos, o crescimento econômico e a adoção de políticas liberais.

Recente pesquisa sobre os fatores determinantes do desmatamento na Amazônia, bem como sobre a valorização de serviços ambientais (Rivas; Mota e Machado, 2008; Santana, 2008 e Rivas, 1998), esbo- çam um panorama sobre os principais problemas do avanço da fronteira agrícola e sobre as causas do desmatamento na região amazônica brasileira, em que são apresentados modelos univariados e multivariados que buscam explicar as causas do desmatamento e proposições, com a finalidade de subsidiar as políticas públicas ambientais regionais. Aidéia central é o aproveitamento dos serviços ambientais proporcionados pelos recursos naturais da região. Os fatores determinísticos do desmatamento da Amazônia foram avaliados também por Reis e Margulis (1991). Os autores utilizaram uma regressão múltipla, com dados de 1985, para estudar uma cross-section de 165 municípios amazônicos. Os resultados mostraram que o desmatamento regional era função de população, área plantada, pecuária (cabeças), madeira, densidade rodoviária e distância à capital estadual.

Estudando a pressão humana sobre os recursos da Amazônia, Barreto et al. (2005), sugeriram que as principais causas do desmatamento são a pecuária de corte (que ocupava até 2005 cerca de $70 \%$ da área desmatada); as culturas anuais, como soja, arroz e milho, principalmente as mecanizadas; o baixo preço da terra; o crescimento populacional; a exploração de madeira e a construção de estradas. A pecuária, a expansão da soja mecanizada, a abertura de estradas clandestinas, a extração irregular de madeira e os grandes investimentos em infra-estrutura, especialmente rodovias de penetração, foram apontados por Alves (2001) como vetores do desmatamento. Além disso,

\begin{tabular}{|c|c|c|c|c|c|c|c|c|c|c|}
\hline aspecto/estudo & $\begin{array}{c}\text { Reis; } \\
\text { M argulis } \\
\text { (1991) }\end{array}$ & $\begin{array}{l}\text { Young } \\
(1998)\end{array}$ & $\begin{array}{c}\text { Pfaff } \\
(1999)\end{array}$ & $\begin{array}{l}\text { Alves } \\
(2001)\end{array}$ & $\begin{array}{l}\text { Margu lis } \\
(2003)\end{array}$ & $\begin{array}{l}\text { Simon; } \\
\text { Garagorry } \\
(2005)\end{array}$ & $\begin{array}{l}\text { Barreto } \\
\text { et al. } \\
(2005)\end{array}$ & $\begin{array}{c}\text { Ewers; } \\
\text { Laurance } \\
(2006)\end{array}$ & $\begin{array}{l}\text { Pfaff } \\
\text { et al. } \\
(2007)\end{array}$ & $\begin{array}{c}\text { Domingues } \\
\text { M artinelli; } \\
\text { Eh leringer } \\
(2007)\end{array}$ \\
\hline $\begin{array}{l}\text { transporte/estradas/ } \\
\text { custos de transporte }\end{array}$ & $\bullet$ & & • & $\bullet$ & $\bullet$ & & $\bullet$ & & $\bullet$ & \\
\hline pecuária & $\bullet$ & & & $\bullet$ & $\bullet$ & & $\bullet$ & $\bullet$ & & $\bullet$ \\
\hline agricultura & $\bullet$ & & & $\bullet$ & & $\bullet$ & $\bullet$ & $\bullet$ & & \\
\hline madeira & $\bullet$ & & & $\bullet$ & & & $\bullet$ & & & \\
\hline população & $\bullet$ & & & & & & $\bullet$ & & & \\
\hline preço da terra & & - & & & & & $\bullet$ & & & \\
\hline preços agrícolas & $\bullet$ & $\bullet$ & & & & & & & & \\
\hline $\begin{array}{l}\text { distância à capital } \\
\text { estadual }\end{array}$ & • & & $\bullet$ & & & & & & & \\
\hline crédito rural & & $\bullet$ & & & & & & & & \\
\hline
\end{tabular}

Quadro 1 - Fatores do desmatamento na Amazônia, segundo diferentes autores Organização dos autores 


\section{Fatores político-econômicos do desmatamento na Amazônia Oriental}

o autor chamou a atenção para a contribuição das práticas de grilagem de terras públicas e da criação de assentamentos rurais.

Margulis (2003) argumentou que no início década de 1990 os desmatamentos estavam relacionados ao crescimento da pecuária de grande e médio porte, diferentemente do ocorrido nas décadas de 1970 e 1980, quando a ocupação dava-se por influência governamental. Já na segunda metade da década de 1990 e no início da década de 2000, os desmatamentos estariam ocorrendo por causa da pecuária de média e grande escalas. A dinâmica de ocupação na década de 1990 obedeceu à lógica majoritariamente privada e tornou-se autônoma. Entre as causas dessa transformação destacam-se as mudanças e adaptações da tecnologia e do gerenciamento da atividade pecuária às condições geoecológicas da Amazônia Oriental, o que permitiu maiores produtividades e menores custos. $\mathrm{O}$ autor identificou ainda que as infra-estruturas, como as estradas, estavam diretamente associadas ao desmatamento regional.

Em uma revisão da literatura acerca dos processos que podem levar à destruição da Floresta Amazônica, Nepstad et al. (2008) discutiram as interrelações dinâmicas entre aspectos ecológicos, econômicos e climáticos, cujos ciclos positivos podem promover à substituição da floresta. Ao destacarem as relações econômicas, eles sugeriram que o aumento da demanda mundial por biocombustíveis e ração animal deve provocar aumento na produção de cana de açúcar no sul do território nacional, o que deve promover um aumento da produção de soja na Amazônia, fato que poderá ampliar os desmatamentos na região. Neste contexto, deve-se atentar para os custos de produção e, principalmente, os preços da soja e da carne bovina, como incertezas críticas, pois eles são capazes de promover diferentes cenários regionais. Pode-se sugerir que estes cenários tendem a convergir para o aumento da pressão por espaços para produção agropecuária na Amazônia, especialmente, na Amazônia Oriental. Além disso, sabe-se que a ampliação das áreas produtivas tem sido realizada com facilidade na região.

O desmatamento na Amazônia não segue um único padrão pré-estabelecido, mas é sim múltiplo em suas origens e processos, dependendo do tempo e da localização espacial. Trata-se de um sistema de relações complexas, cujo conhecimento deve ser aprofundado para um melhor planejamento do desenvolvimento regional. Na região da fronteira agropecuária, essas relações, assim como o desmatamento, são mais intensas do que nas porções no noroeste da Amazônia.

De maneira geral, destacam-se neste estudo como elementos-chave dessa dinâmica do desmatamento regional: atividades produtivas (produção de grãos, madeira e pecuária), incêndios florestais e a criação de áreas protegidas e assentamentos rurais. Gerado por políticas de desenvolvimento que não foram capazes de atender as necessidades de uma grande parcela da população, pela provisão de infra-estruturas (principalmente rodoviárias) e pelo aumento do preço da terra, entre outros fatores, encontramo-nos em um período histórico de grande pressão por terras na Amazônia. Esta grande pressão social garante o aumento de políticas públicas de reforma agrária. (Barreto et al., 2005). Isso aumenta a pressão por terras e políticas de reforma agrária. A carência de fiscalização, além da extração e venda da madeira, geram um ambiente favorável à ampliação das intensidades das disputas pela posse da terra. Isso, em conjunto com a morosidade do processo de titulação, promove o "desmatamento por precaução", mais violência e maiores índices de criminalidade (Hoefle, 2006). Assim, o ambiente torna-se cada vez mais inóspito ao exercício da fiscalização, levando a um novo ciclo de auto-amplificação no sistema.

A infra-estrutura, elemento importante nas dinâmicas do sistema, pode causar desmatamento diretamente ou pela grande influência que tem sobre outros elementos, como a criação de estruturas e serviços suporte à pecuária. Isso amplia a lucratividade do setor e faz crescer os rebanhos e as áreas de pastagens, o que gera aumento de investimentos em equipamentos para a pecuária (Escada et al., 2005). Os preços mais baixos da terra e a produtividade mais alta tornam as pastagens mais lucrativas na Amazônia do que em outras regiões. Esses aspectos possibilitaram o fortalecimento do mercado de terras na região. A facilidade de comercialização de terras origina, geralmente, uma corrida pela posse, com conse- 


\section{Sustentabilidade em Debate}

quiente desmatamento, pois este é o meio de se garantir a propriedade (Muchagata e Brown, 2003).

A produção de grãos é outro relevante fator de desmatamento regional e a sua sinergia com outras atividades produtivas exige atenção especial. A cultura de grãos tem pressionado a Amazônia, destacadamente as áreas mais externas. Isso causa um aumento dos preços da terra. Além disso, as áreas ocupadas pela pecuária, por terem baixo valor, proporcionam ganhos para o pecuarista, que promove um aumento do rebanho e conseqüentemente, novos desmatamentos para dar lugar a pastagens. Esse fato tem levado a um deslocamento da pecuária para as áreas mais internas da floresta, promovendo o desmatamento e abertura de novas frentes de expansão (Margulis, 2003) que são viabilizadas socialmente pelos interesses convergentes entre madeireiros, trabalhadores rurais e agricultores despossuídos.

O crescimento da agricultura, assim como da pecuária, promove aumento do número de queimadas e incêndios descontrolados, com conseqüente perda da cobertura florestal. A queima da floresta reduz a sua capacidade de sobreviver a novas queimadas, ou seja, ela fica mais suscetível à recorrência do fogo, perde a sua capacidade original de regeneração e torna-se um tipo de savana ou cerrado. A queimada ainda é o instrumento mais usado para limpar o solo imediatamente após o desmatamento para estabelecer a pequena agricultura e para a manutenção de pastagem. A perda de grande parte da cobertura florestal, principalmente por incêndios, emite uma grande quantidade de $\mathrm{CO}_{2}$ e outros gases à atmosfera e reduz a capacidade de a floresta absorver $\mathrm{CO}_{2}$ (seqüestro). Disso decorre um aumento nas emissões de $\mathrm{CO}_{2}$ à atmosfera que, juntamente com as emissões globais, em médio prazo, pode contribuir significativamente para acelerar os efeitos das mudanças climáticas globais. O aquecimento leva a um aumento de temperatura em toda a região, aumentando a suscetibilidade das florestas a incêndios. Além disso, promove alterações nos regimes de chuvas. Algumas projeções indicam, que deverá ocorrer um aumento geral na intensidade das chuvas na Amazônia (IPCC, 2007), exceto em trechos de sua porção extremooriental (Ometto et al., 2005), onde poderá ocorrer redução delas.
O previsto aumento de incidência de chuvas em quase toda a Amazônia deve causar grandes impactos, entre eles maior incidência de pragas e doenças e a redução da capacidade de execução de colheita mecanizada. Estes fatores prejudicariam a produção agrícola e para a pecuária, que podem sofrer uma grande redução em longo prazo na região, delegando para as futuras gerações um grande passivo ambiental.

Neste contexto pode-se argüir como prover uma melhoria da qualidade de vida das presentes gerações de seres humanos, principalmente aqueles que vivem na região, em combinação com a proteção dos recursos naturais, a fim de permitir o seu aproveitamento pelas futuras gerações. Este é um grande desafio para a Amazônia. O fato é que ainda prevalecem na Amazônia práticas de apropriação dos recursos naturais sem qualquer intervenção ou controle público efetivo. $\mathrm{O}$ registro irregular de terras é incentivado pela ineficiência da fiscalização, pela precariedade das instituições locais, pelas grandes extensões territoriais e pelo envolvimento de autoridades por interesses particulares (Sayago e Machado, 2004). Neste ambiente, as demandas de mercado, tanto doméstico como internacional, impulsionam livremente o crescimento econômico e debilitam as políticas ambientais na Amazônia, principalmente, em sua porção oriental.

\section{Fatores Político-Econômicos do Desmatamento na Porção oOiental do Bioma Amazônia}

\section{Amazônia Oriental: uma breve caracterização}

A porção oriental do bioma Amazônia contém 403 (dos 551 municípios do bioma) (IBGE, 2006) e uma população residente de 13,17 milhões de habitantes (IBGE, 2007). O solo está, em grande maioria, coberto por florestas. São 1,22 milhões $\mathrm{km}^{2}$ florestados (INPE, 2008) em um território de 2,34 milhões $\mathrm{km}^{2}$ (IBGE, 2000). Deste total, 0,88 milhão $\mathrm{km}^{2}(37,61 \%)$ encontra-se abrigado em unidades de conservação ou terras indígenas (MMA, 2009). Além disso, o Brasil tem uma extensa legislação ambiental que incide sobre a Amazônia, de forma a combater, dentre outros, o desmatamento regional. Nas propri- 
edades privadas, a obrigatoriedade de se preservar $80 \%$ da área como reserva legal além das Áreas de Preservação Permanentes (APPs), se houverem corpos d'água no interior da propriedade, é uma das mais restritivas, apesar de ser historicamente de difícil cumprimento (Barreto et al. 2005). Foram desmatados $468 \mathrm{mil} \mathrm{km}^{2}$ de florestas nativas na Amazônia Oriental (INPE, 2008). O Gráfico 1 destaca a evolução da área desmatada nos últimos anos.

Pode-se perceber uma forte queda nos níveis de desmatamento anual entre o período de 2003/2004 e 2005/2006. São muitos os fatores apontados para este comportamento, entretanto, são comuns as flutuações em séries temporais do desmatamento na Amazônia (Ewers, Laurance e Souza Jr., 2008). As forças motrizes deste comportamento cíclico ainda são de difí- da embocadura, que se estende do sul do Amapá até São Luiz, incluindo Belém; 2) o da fronteira de preservação, que engloba parte do noroeste do Pará e nordeste do Amapá, incluindo a fronteira com a Guiana; 3) a dos núcleos de modernização do leste e sudeste do Pará; 4) a do corredor Araguaia-Tocantins; 5) a do vale do Amazonas; 6) o da Transamazônica e o das frentes de expansão, 7) Terra do Meio e 8) cunha do Tapajós.

As atividades produtivas regionais historicamente relacionadas ao desmatamento regional são a pecuária bovina, a agricultura (principalmente a produção de grãos em grande escala), a extração de madeira em tora, a mineração, a produção de carvão vege-

\section{Área desmatada $\left(\mathrm{km}^{2}\right)$}

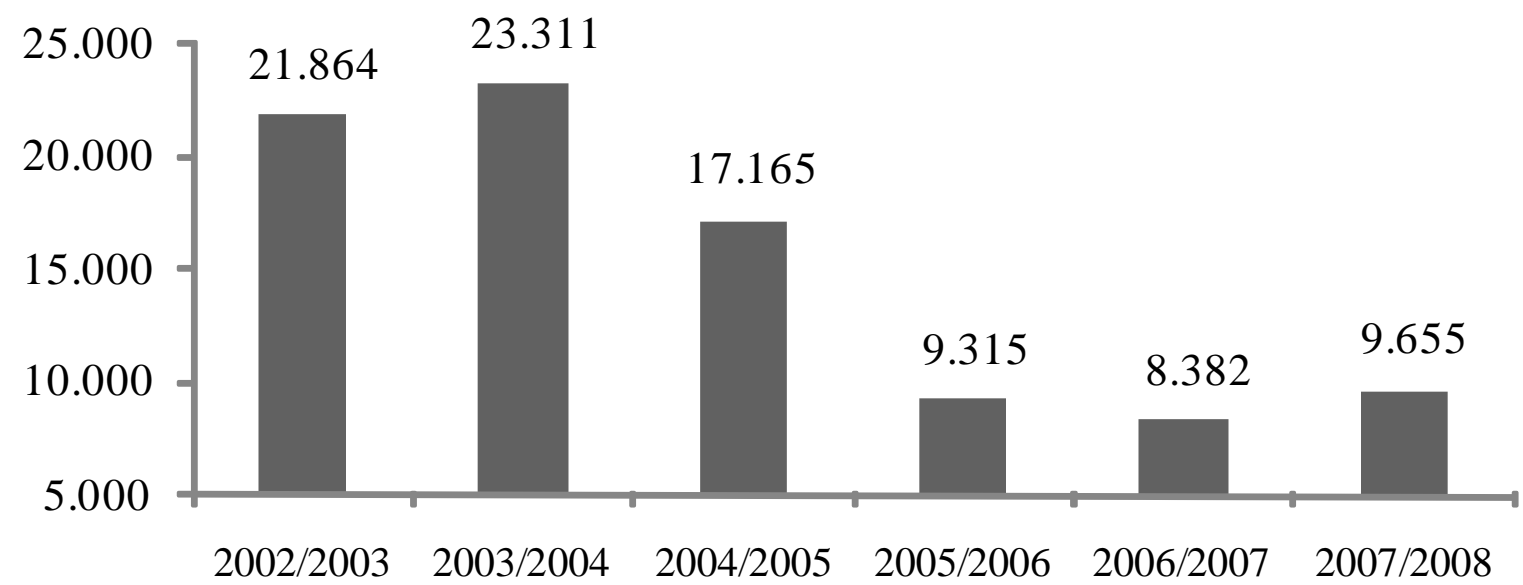

Gráfico 1 - Evolução da área desmatada anualmente na Amazônia Oriental, 2003-2008

Fonte: INPE/PRODES

Organização dos autores

cil compreensão, por causa da carência de séries temporais mais longas e completas.

A Amazônia Oriental é uma região heterogênea em suas formas de ocupação territorial e temporal. A sua ocupação territorial foi historicamente influenciada por forças externas a este território, como políticas públicas federais de desenvolvimento e os preços dos produtos agropecuários e minerais, associados à localização e às características ambientais (clima, qualidade do solo e dos corpos d'água), que variam entre as suas sub-regiões (Becker, 2004): 1) a do arco tal. Mais recentemente (BRASIL, 2007), aponta-se para a importância e necessidade de investimento na produção do extrativismo florestal não-madeireiro. A Tabela I mostra a evolução recente desses aspectos na região de estudo.

Em 2007 houve uma queda de 7,75\% no número total de cabeças de gado bovino (49,541 milhões) em relação a 2006. Ao contrário, a área plantada cresceu de 79,815 mil km² em 2006 para 92,278 mil km² em 2007. A grande correlação espacial entre esses dois fatores possibilita sugerir que nesse período par- 


\section{Sustentabilidade em Debate}

Tabela I: Evolução de atividades produtivas na Amazônia Oriental, 2001-2007

\begin{tabular}{lrrrrrrr}
$\begin{array}{l}\text { Atividades } \\
\text { produtivas }\end{array}$ & 2001 & 2002 & 2003 & 2004 & 2005 & 2006 & 2007 \\
\hline rebanho bovino $($ mil cabeças) & 36.588 & 40.414 & 44.961 & 52.472 & 54.822 & 53.378 & 49.541 \\
área plantada $\left(\mathrm{km}^{2}\right)$ & 48,733 & 59.288 & 68.709 & 82.267 & 92.204 & 79.815 & 92.278 \\
madeira em tora $\left(\mathrm{mil} \mathrm{m}^{3}\right)$ & 15.958 & 15.922 & 14.566 & 13.586 & 10.909 & 10.659 & 10.305 \\
& 1.082 .60 & 1.221 .10 & 1.560 .27 & 412.59 & 687.08 & 741.00 & 745.18 \\
carvão vegetal $(\mathrm{T})$ & 9 & 2 & 3 & 3 & 6 & 4 & 1 \\
& & & & 102.62 & 112.29 & 131.06 & 134.43 \\
extrativismo não-madeireiro $(\mathrm{R} \$ 1000)$ & 100.292 & 98.736 & 93.250 & 2 & 4 & 5 & 4 \\
\hline
\end{tabular}

Fonte: organizado pelos autores a partir dos dados primários do IBGE - Pesquisa da Pecuária Municipal, Pesquisa da Produção Agrícola Municipal e Pesquisa da Produção do Extrativismo Vegetal e da Silvicultura (2001-2007).

te das áreas de pastagens foi substituída por lavouras. Quanto ao extrativismo florestal, a produção de $10.659 \mathrm{mil} \mathrm{m}^{3}$ de madeira em tora em 2006 caiu para $10.305 \mathrm{mil} \mathrm{m}^{3}$ em 2007. Já a produção de carvão vegetal cresceu continuamente desde 2004. Em 2006 foram 741 mil toneladas e em 2007 esta produção subiu para 745 mil. A produção do extrativismo nãomadeireiro teve um pequeno crescimento em 2007 , $\mathrm{R}$ \$ 134 milhões, recuperando-se da queda sofrida em 2006, expressa pela cifra de $\mathrm{R} \$ 131$ milhões. Esses e outros fatores foram avaliados e integram os resultados deste estudo.

\section{Procedimentos metodológicos}

A pesquisa foi realizada em quatro etapas básicas. Inicialmente, foi feito um estudo aprofundado da literatura nacional e internacional sobre o desmatamento da Amazônia e as suas causas. A segunda etapa foi a construção de um banco de dados sobre os municípios pertencentes à área de domínio do bioma Amazônia (estados do Acre, Pará, Mato Grosso, Tocantins e Maranhão). Os dados foram coletados principalmente junto ao Instituto Brasileiro de Geografia e Estatística (IBGE), principalmente, a Produção da Pecuária Municipal, a Produção Agrícola Municipal e a Produção da Extração Vegetal e da Silvicultura. Dados sobre a variável principal, os desmatamentos, vêm do Pro- grama de Cálculo do Desflorestamento da Amazônia (PRODES) do Instituto Nacional de Pesquisas Espaciais (INPE). De 1988 a 2002, a interpretação das imagens foi realizada por meio de interpretação visual de imagens impressas em papel fotográfico. A partir de 2003, o INPE adotou o processo de interpretação assistida pelo computador, chamado de programa PRODES Digital para distingui-lo do processo anterior. As áreas protegidas e as distâncias das sedes dos municípios ao escritório do IBAMA regional mais próximo foram calculadas utilizando-se a projeção Albers Equal Area Conic na ferramenta Arc Gis 9.3, a partir das respectivas malhas digitais (shapefiles) disponibilizadas pelo Ministério do Meio Ambiente (MMA).

A terceira etapa envolveu a elaboração do modelo econométrico capaz de representar as taxas de desmatamento anual em função de políticas públicas, aspectos institucionais e atividades produtivas. Foi realizada uma regressão linear múltipla por Mínimos Quadrados Ordinários, empregando a logaritmização dupla (utilizando os logaritmos naturais tanto da variável dependente como das independentes). A regressão múltipla envolve o estudo da dependência de uma variável em relação a duas ou mais variáveis distintas, com o objetivo de estimar o valor médio da variável dependente em função dos valores das variáveis explicativas (Gujarati, 2000). O modelo gerado nes- 
te estudo para o comportamento das taxas anuais de desmatamento $\left(T x D_{i}\right)$ em função das variáveis explicativas $x_{i}$ pode ser descrito como:

É importante atentar que buscou-se nesta pesquisa usar os fatores (driving forces) relacionados em primeiro nível (diretas) com as taxas anuais de desmatamento municipais, inicialmente identificadas nas dinâmicas do desmatamento reveladas pela literatura. Neste sentido, este estudo distingue-se dos demais, que focalizaram a construção de uma equação econométrica válida para previsão, sem esta preocupação. Por isso, os testes $\mathrm{R}^{2}$ e F de Fisher devem ser mais baixos e a multicolinearidade incidente no modelo tende a ser leve.

\section{Fatores do desmatamento na Amazônia Oriental}

$\ln \left(T x D_{i}\right)=\beta_{0}+\beta_{1} \cdot \ln \left(x_{1}\right)+\beta_{2} \cdot \ln \left(x_{2}\right)+\cdots+\beta_{n} \cdot \ln \left(x_{n}\right)+e$

As variáveis envolvidas foram analisadas utilizando-se suas taxas espaciais, ou seja, seus valores divididos pelas áreas territoriais municipais. Isto foi feito para eliminar vieses causados por diferentes dimensões nos casos, reduzindo a incidência multicolinearidade e o aumento da clareza na interpretação dos resultados.

O modelo estimado para o período 2007/2008 forneceu parâmetros aceitáveis quanto a suas significâncias estatísticas $\left(\mathrm{R}_{a d j}^{2}=0,628 ; \mathrm{F}=57,175\right.$;
$S I G .=0,000)$. Os resultados dos coeficientes da regressão múltipla por série de corte (2007/2008), apresentados pela Tabela II, revelam que a taxa anual de desmatamento - $\mathrm{TxD}_{\mathrm{i}}$ é função, diretamente: da taxa de crescimento da área agropecuária (pastagens e lavouras) - TxC_Agropecuária; da taxa do valor da produção de madeira em tora - Tx_Madeira; da taxa do valor da produção de carvão vegetal - Tx_Carvão; da taxa da distância da sede do município ao escritório regional do IBAMA mais próximo - TxD_Ibama; e da taxa de estoque florestal - Tx_Área Florestada. E, inversamente: da taxa do valor da produção do extrativismo florestal não-madeireiro Tx_Extrativismo e da taxa de áreas protegidas (unidades de conservação e terras indígenas) - Tx_Área Protegida.

O coeficiente â em uma regressão utilizando a logaritmização dupla permite a imediata revelação das elasticidades da variável dependente em relação às variáveis explicativas. Dessa forma, pode-se afirmar que um aumento de $1 \%$ na taxa de crescimento anual da área agropecuária corresponderá a um aumento de $0,335 \%$ nas taxas anuais de desmatamento. Ou seja, para cada $6,77 \mathrm{~km}^{2}$ de incremento na área agropecuária, deve ocorrer um aumento de $3,44 \mathrm{~km}^{2}$ no desmatamento.

Estudos sugerem a pecuária (Reis e Margulis, 1991; Margulis, 2003; Domingues, Martinelli e Ehleringer, 2007) e a agricultura (Simon e Garagorry, 2002; Vieira e Proctor, 2007), especialmente de grãos (Perz, 2003; Morton et al., 2006; Steward, 2007), como principais fatores do desmatamento, conferin-

Tabela II - Resultados para os coeficientes da regressão múltipla por $M Q O$

\begin{tabular}{|c|c|c|c|c|c|c|c|}
\hline & \multicolumn{3}{|c|}{ c oeficie $n$ te $s$} & \multirow[b]{2}{*}{$\mathrm{t}$} & \multirow[b]{2}{*}{ Sig. } & \multicolumn{2}{|c|}{ colinearidade } \\
\hline & $\beta$ & $\mathrm{dp}$ & B e ta & & & Tolerance & V IF \\
\hline (c onsta nte) & $-3,639$ &, 254 & - & $-14,298$ &, 000 & - & - \\
\hline $\ln \left(\mathrm{TxC}_{-} \mathrm{A}\right.$ gropec uária $)$ &, 355 &, 045 &, 359 & 7,885 &, 000 &, 764 & 1,310 \\
\hline $\ln \left(\mathrm{Tx}_{-} \mathrm{M}\right.$ ade ir a $)$ &, 143 & ,038 &, 158 & 3,773 &, 000 &, 900 & 1,111 \\
\hline $\ln ($ Tx_Ca rvão $)$ &, 166 &, 021 & ,330 & 7,875 &, 000 &, 900 & 1,111 \\
\hline $\ln \left(\mathrm{Tx}_{-}\right.$Ex trativis mo $)$ &,- 118 &, 034 &,- 145 & $-3,451$ &, 001 &, 897 & 1,115 \\
\hline $\ln \left(\mathrm{T} x \mathrm{D} \_\mathrm{Ib}\right.$ a ma $)$ &, 084 &, 028 &, 124 & 3,007 &, 003 & ,937 & 1,067 \\
\hline ln $\left(\mathrm{Tx}_{-}\right.$Áre a Protegida) &,- 078 &, 020 &,- 171 & $-3,919$ &, 000 &, 828 & 1,208 \\
\hline ln $\left(\mathrm{Tx}_{-}\right.$Áre a Floresta $\left.\mathrm{da}\right)$ &, 904 & 057 &, 716 & 15,759 &, 000 &, 767 & 1,304 \\
\hline
\end{tabular}

* variável dependente: $\ln \left(T x D_{i}\right)$ 


\section{Sustentabilidade em Debate}

do-lhes um grande percentual de influência. Entretanto, pode-se questionar a utilização nesse tipo de interpretação das variáveis do tipo estoque (Lambin et al., 2001). Por exemplo, se não houver variação na área agropecuária, a influência desse fator tende a ser baixo, pois o desmatamento ocorre somente por mobilidade interna. Mas, a utilização dessas variáveis tende a agregar fatores correlacionados historicamente tanto com a agricultura e a pecuária como com a produção de madeira ou carvão, alterando os seus coeficientes e os de outros fatores explicativos.

Outro aspecto que deve ser observado é a forte correlação entre as atividades pecuária e agrícola. São dinâmicas semelhantes, que envolvem a ocupação do território, diferente das produções de madeira e carvão, que são provisórias e altamente itinerantes. Além disso, as áreas das propriedades agropecuárias podem ser facilmente convertidas de uma atividade em outra, dependendo das oportunidades. Esses fatores devem assim ser levados em consideração em qualquer análise do processo de desmatamento na Amazônia, pois a sua não-observação pode afetar a análise do fenômeno.

A produção de madeira em tora é outro fator causal do desmatamento vastamente abordado na literatura pertinente (Arima et al., 2005; Lorena e Lambin, 2009). Historicamente, a madeira vem perdendo espaço na Amazônia. A produção de madeira em tora teve grande força até meados da década de 1990. A partir de então houve grande queda na produção oficial. Todavia, a quantidade produzida ainda pode ser considerada elevada. Na porção oriental do bioma, os resultados sugerem que um crescimento de $1 \%$ na produção de madeira em tora equivale a um aumento de 0,143\% nas taxas anuais de desmatamento. Deve-se ressaltar que não estão diferenciadas aqui as formas de exploração da madeira. A exploração com utilização de adequado manejo florestal tende a promover significativa redução de danos (Mota et al., 2008; Ellis e Porter-Bolland, 2008), apesar de ocorrer em menor proporção.

O contínuo e intenso crescimento recente da produção de carvão na região é preocupante. Por sua característica itinerante, a produção deste que pode ser considerado o menos nobre dos produtos florestais tende a ser de difícil fiscalização. Apesar disso, pouco se aborda este produto como causa relevante do desmatamento na Amazônia (Barreto et al., 2005). Todavia, os resultados mostram que a sua influência foi maior que a da produção de madeira em tora. $\mathrm{O}$ coeficiente estimado sugere que para cada aumento de $1 \%$ na produção de carvão vegetal, há uma elevação de $0,166 \%$ nas taxas anuais de desmatamento. Ou seja, o incremento de mil toneladas de carvão anual na produção tende a elevar a área desmatada anual em $247 \mathrm{~km}^{2}$. Portanto, urge um acompanhamento mais sistemático dessa produção. Além disso, o processo de fiscalização deve ser mais rigoroso com este tipo de atividade na Amazônia Oriental.

Recentemente tem-se demonstrado especial interesse pelas atividades tradicionais dos habitantes da floresta (Ostrom, 2008). O extrativismo florestal não-madeireiro (alimentos, fibras, fármacos, ceras, óleos) tem sido sugerido como um fator importante para a promoção do desenvolvimento sustentável da Amazônia. Na Amazônia Oriental, entretanto, a atividade ainda é pouco desenvolvida em relação ao seu potencial. Grande maioria da produção é composta por produtos alimentícios e oleaginosos. Para ilustrar este baixo aproveitamento, pode-se verificar que, em 2007, dos mais de R \$ 134,43 milhões produzidos pelo extrativismo não-madeireiro na Amazônia Oriental, R\$ 115,65 mil (86,02 \%) são produtos voltados à alimentação (IBGE - Produção do Extrativismo Vegetal e da Silvicultura, 2007). A produção de ceras foi de somente $\mathrm{R} \$ 1,84 \mathrm{mil}$ $(1,37 \%)$ e a produção voltada para produção de fármacos de apenas R \$104, ou seja, menos de 0,01\% do valor total da produção do extrativismo não madeireiro.

Apesar desse baixo aproveitamento, o extrativismo florestal não madeireiro surge como importante fator de proteção florestal contra o processo de desmatamento. Os resultados evidenciam que um aumento de $1 \%$ no valor da produção extrativista traz uma redução de $0,118 \%$ na taxa anual de desmatamento. Não foram localizados estudos aprofundados sobre as relações entre o extrativismo e a proteção florestal na Amazônia. Assim, esta evidência sugere a necessidade de maior aprofundamento nos estudos sobre as suas relações com a floresta, 


\section{Fatores político-econômicos do desmatamento na Amazônia Oriental}

com o mercado e com os outros fatores do desmatamento regional.

Outro aspecto que vem sendo apontado como causa da redução do desmatamento na Amazônia é a melhoria dos processos de fiscalização (BRASIL, 2007; Nepstad et al.; 2010). Os resultados deste estudo mostram que, nesta porção do território, as taxas anuais de desmatamento são função da distância dos municípios (sedes) até o escritório regional do Ibama mais próximo. Ou seja, quanto maior a distância, maiores as taxas de desmatamento. Para uma redução de $1 \%$ na distância ao escritório regional, há, em média, uma redução de $0,084 \%$ nas taxas de desmatamento municipal. Essas evidências podem estar relacionadas a três aspectos. Primeiro, ao processo de fiscalização das atividades antrópicas, à infraestrutura dos escritórios e à própria inibição pela presença do órgão. Neste sentido, pode-se sugerir a investigação desses aspectos e das suas relações com o desmatamento regional.

As áreas protegidas consistem na mais utilizada política de proteção ambiental no Brasil. Neste trabalho foram compostas pela soma das áreas das unidades de conservação de proteção integral, unidades de conservação de uso sustentável e terras indígenas. São apontadas como importantes para a contenção do desmatamento na Amazônia, entretanto, o seu principal propósito é proteger determinadas áreas consideradas mais relevantes por diversos aspectos. Afirma-se (Ferreira, Venticinque e Almeida, 2005; Clark, Bolt e Campbell, 2008) que elas são relevantes para a redução do desmatamento regional. Os resultados deste estudo confirmam essas conclusões. Para um aumento de $1 \%$ na extensão das áreas protegidas, pode-se esperar uma redução de $0,078 \%$ nas taxas anuais de desmatamento.

Apesar de sua grande ocupação percentual do território e de sua capacidade de resguardar determinadas porções territoriais, sugere-se que a sua influência não seja tão alta. Isso pode ocorrer, pois ainda há grande quantidade de área florestada externa às áreas protegidas aqui agrupadas. Além disso, a pecuária e a agricultura, atividades que ocupam também para assegurar os direitos de propriedade, buscam áreas externas a esses espaços protegidos para ocupação definitiva. Isso leva a uma ocupação alternati- va, grande parte sobre áreas florestadas não-protegidas. Há grande estoque florestal disponível que ocupa um percentual significativo do território ainda nãoantropizado. Os resultados mostram que a taxa de cobertura florestal municipal é, entre os fatores aqui observados, o mais relevante para o comportamento das taxas de desmatamento. Uma redução de $1 \%$ no estoque florestal equivale a uma redução de $0,904 \%$ nos desmatamentos anuais.

Por intermédio dos coeficientes padronizados 'Beta', é possível sugerir diferenças nas influências desses fatores nas taxas anuais de desmatamento no período de 2007/2008. A atividade econômica que mais influenciou o desmatamento regional foi a agropecuária, mas a produção de carvão vegetal também teve significativa influência. Isso pode ter ocorrido por causa do acentuado crescimento do carvão, aliado a queda nas taxas de crescimento da área agropecuária e a existência de uma área ainda ociosa nas propriedades agropecuárias, pois a área efetivamente ocupada em 2006 foi bem menor que em 2007, permitindo a reocupação.

Sugere-se (Ostrom, 2009) que a presença das comunidades tradicionais e a valorização da floresta pelos beneficiários diretos do extrativismo representam uma força capaz de reduzir a vulnerabilidade das florestas. O extrativismo teve uma influência inversa e significativa nas taxas de desmatamento (0,145), semelhante até mesmo à das áreas protegidas $(0,171)$, conforme evidenciado por seus respectivos coeficientes Beta. Neste sentido, na Amazônia, as porções florestais não-protegidas são as mais vulneráveis, conforme demonstram os resultados deste estudo, o incremento do extrativismo pode se constituir em uma eficiente estratégia de proteção florestal.

Os indicadores de colinearidade (Tolerance $e$ Value Inflation Factor - VIF) mostram uma pequena relação inversa entre o crescimento da área agropecuária e a área florestada. Isso pode estar ocorrendo devido à importância histórica da atividade agropecuária como promotora do desmatamento acumulado regional. Pode-se verificar que a incidência de multicolinearidade no modelo é leve e que, desta forma, os coeficientes podem ser interpretados sem problemas. 


\section{Sustentabilidade em Debate}

\section{Considerações finais}

Os esforços para o desenvolvimento da Amazônia esbarram na ineficiência da proteção dos recursos naturais. Percebe-se a ameaça aos recursos da Amazônia pelas atividades produtivas extensivas, que, em muitos casos, podem ser entendidas como pegadas ecológicas de outras nações e de outras regiões que demandam esses recursos. Por outro, o uso sustentável dos recursos naturais da Amazônia pode ser uma grande oportunidade estratégica para o Brasil em um contexto de transformações globais, avanço tecnológico e biotecnológico, supervalorização social da natureza, escassez de recursos naturais, entre outros aspectos.

O desmatamento recente na Amazônia Oriental é função, entre outros fatores, da agropecuária, da produção de madeira em tora e da produção de carvão e do estoque florestal. Por outro lado, as áreas protegidas, a produção extrativista não madeireira e a proximidade a um escritório regional do Ibama são aspectos que podem ser entendidos como protetores da floresta contra o desmatamento promovido por aqueles.

Entende-se que a problemática do desmatamento da Amazônia é complexa, por envolver aspectos sociais, econômicos e ambientais em interação dinâmica não-linear. Neste sentido, a capacidade de regulação do processo de desenvolvimento envolve entes de diversos níveis (federal, estadual e municipal) que têm capacidades diversas em termos de recursos financeiros, materiais e humanos. Pode-se questionar se esses aspectos colaboram para a ineficiência da utilização preponderante dos instrumentos de comando e controle na proteção dos recursos naturais nesta porção do bima. Por isso, podese sugerir que o uso instrumentos econômicos auxiliares pode vir a gerar resultados mais expressivos.

As relações da criação pecuária bovina e da produção de grãos com os desmatamentos preocupam frente à questão do desenvolvimento regional, por serem atividades extensivas que, na maioria dos casos, geram concentração de renda, e não uma maior distribuição dela. Além disso, as vastas porções territoriais exigidas para pastagens e plantações indicam que estas atividades, da forma como estão ocor- rendo, podem ser consideras inadequadas ao desenvolvimento sustentável regional.

A carência de conhecimentos disponíveis sobre aspectos da dinâmica ecológico-econômica regional não deve ser vista como um empecilho à ação, mas sim como um direcionamento para a geração de maior conhecimento e para precaução quanto ao uso dos recursos naturais regionais. Por esses aspectos, podese sugerir os seguintes pontos, frente à necessidade de interromper o desmatamento contínuo da Amazônia Oriental e promover o desenvolvimento sustentável regional: 1) promover o aumento da produtividade das áreas já ocupadas; 3 ) estudar alternativas de produção nas áreas atualmente ocupadas pela produção de grãos e pecuária bovina; 4) restringir a produção de madeira sem o adequado manejo florestal; 5) rever a política de incentivos e custeio para a pecuária bovina e para a agricultura; 6) incentivar o extrativismo não-madeireiro, principalmente em florestas externas às áreas protegidas; e 7) ampliar a presença do Ibama.

\section{Referências Bibliográficas}

Albagli, S. (2001) "Amazônia: fronteira geopolítica da biodiversidade". Parcerias Estratégicas, $\mathrm{n}^{\circ}$ 12: 6 . Alves, D. S. (2001) "O processo de desmatamento na Amazônia”. Parcerias Estratégicas, Vol. 12: 259275.

Angelsen, A.; Kaimowitz, D. (1999) "Rethinking the causes of deforestation: lessons from economic models". The World Bank Research Observer, Vol. 14, n. 1: 73-98.

Arima, E. Y.; Walker, R. T.; Perz, S. G.; Caldas, M. (2005) "Loggers and Forest Fragmentation: Behavioral Models of Road Building in the Amazon Basin". Annals of the Association of American Geographers, Vol. 95, n 3: 525-541.

Barbier, E. B. (2001) "The economics of tropical deforestation and land use: an introduction to the special issue". Land Economics, Vol. 77, $n^{\circ} .2$ : 155171.

Barreto, P.; Souza Jr., C.; Noguerón, R.; Anderson, A.; Salomão, R. (2005) "Pressão humana na floresta amazônica brasileira". Belém, World special issue". Land Economics, Vol. 77, ${ }^{\circ}$. 2: 155-171. 
Barreto, P.; Souza Jr., C.; Noguerón, R.; Anderson, A.; Salomão, R. (2005) "Pressão humana na floresta amazônica brasileira”. Belém, World

Resource Institute.

Becker, B. K. (2004) “Amazônia: geopolítica na virada do III milênio". Rio de Janeiro: Garamond. (2005) "Geopolítica da Amazônia”. Es-

tudos Avançados, Vol. 19, n. 53: 71-86.

Börner, J.; Mendoza, A.; Vosti, S. A. (2007)

"Ecosystem services, agriculture, and rural poverty in the Eastern Brazilian Amazon: interrelationships and policy prescriptions". Ecological Economics, Vol. 64: 356-373.

Brasil (2007) "Plano Amazônia Sustentável: diretrizes para o desenvolvimento sustentável da Amazônia Brasileira". Brasília: Ministério do Meio Ambiente. Bürgi, M.; Hersperger, A. M.; Schneeberger, N. (2004) "Driving forces of landscape change - current and new directions". Landscape Ecology, Vol. 19: 857-868.

Cattaneo, A. (2001) "Inter-regional innovation in Brazilian agriculture and deforestation in the Amazon: income and environment in the balance". Environment and Development Economics, Vol. 10: 485-511.

Clark, S., Bolt, K., Campbell, A. (2008) "Protected areas: an effective tool to reduce emissions from deforestation and forest degradation in developing countries?" Cambridge, U.K. Working Paper, UNEP World Conservation Monitoring Centre.

DeFries, R. S.; Foley, J. A.; Asner, G. P. (2004) "Landuse choices: balancing human needs and ecosystem function". Frontiers in Ecology and Environment, Vol. 2, n० 5: 249-257.

DeRosnay, J. (1975) "Le Macroscope: vers une vision globale". Paris: Senil.

Desfontaines, P. L. (1957) "L'introduction du bétail en Amérique Latine". Les Cahiers d'Outre Mer, Vol. 10: 5-22.

Diamond, J. (2006) "Colapso: como as sociedades escolhem o fracasso ou o sucesso". Rio de Janeiro: Record.

Domingues, T. F.; Martinelli, L. A.; Ehleringer, J. R. (2007) "Ecophysiological traits of plant functional groups in forest and pasture ecosystems from eastern Amazônia, Brazil". Plant Ecology, n.193: 101-112. Ellis, E. A.; Porter-Bolland, L. (2008) “Is community- based forest management more effective than protected areas? A comparison of land use/land cover change in two neighboring study areas of the Central Yucatan Peninsula, Mexico. Forest Ecology and Management, Vol 256: 1971-1983.

Escada, M. I. S.; Vieira, I. C. G.; Kampel, S. A.; Araújo, R.; Veiga, J. B.; Aguiar, A. P. D.; Veiga, I.; Oliveira,M.; Pereira, J. L. G.; Carneiro Filho, A.; Fearnside, P. M.; Venturieri, A.; Carriello, F.; Thales, M.; Carneiro, T. S. G.; Monteiro, A. M. V.; Câmara, G. (2005) "Processos de ocupação nas novas fronteiras da Amazônia (o interflúvio do Xingu/ Iriri)". Estudos Avançados, Vol. 19, n . 54: 9-23.

Ewers, R. M.; Laurance, W. F. (2006) "Scaledependent patterns of deforestation in the Brazilian Amazon". Environmental Conservation, Vol. 33, $\mathrm{n}^{\circ}$. 3: 203-211.

Ewers, R. M.; Laurance, W. F.; Souza Jr, C. M. (2009) "Temporal fluctuations in Amazonian deforestation rates". Environmental Conservation, Vol. 35, $\mathrm{n}^{\circ} 4$ : 303-310.

Fearnside, P. M. (1997) "Greenhouse gases from deforestation in Brazilian Amazonia: net committed emissions". Climatic Change, Vol. 35: 321-360.

Ferreira, L. V.; Venticinque, E.; Almeida, S. (2005) "O desmatamento na Amazônia e a importância das áreas protegidas”. Estudos Avançados, Vol. 19, n 53 : 157-165.

Gujarati, D. M. (2000) "Econometria básica". São Paulo: Makron Books.

Hoefle, S. W. (2006) "Twisting the knife: Frontier violence in the central Amazon of Brazil". Journal of Peasant Studies, Vol. 33, n . 3: 445-478.

Huston, M. A. (2005) "The three phases of land-use change: implications for biodiversity". Ecological Applications, Vol. 15, n 6: 1864-1878.

Igliori, D. C. (2006) "Economia espacial do desenvolvimento e da conservação ambiental: uma análise sobre o uso da terra na Amazônia". Ciência e Cultura, Vol. 58, $n^{\circ}$. 1: 29-33.

Intergovernmental Panel on Climate Change - IPCC (2007) "Climate Change 2007: Synthesis Report Summary for Policymakers". Fourth Assessment Report, Cambridge Univ. Press.

Instituto Brasileiro de Geografia e Estatística - IBGE (2002) "Estimativas de temperatura e precipitação 


\section{Sustentabilidade em Debate}

para os municípios da Amazônia Legal”, IBGE, 1996. Disponível em http://www.ibge.gov.br. Acesso em 20 de setembro de 2008.

"Informações Básicas Municipais", IBGE, 2000 a 2007. Disponível em http:// www.ibge.gov.br. Acesso em 20 de setembro de 2008. ."Produção da Extração Vegetal e da Silvicultura", IBGE, 2000 a 2006. Disponível em http:/ /www.ibge.gov.br. Acesso em 20 de setembro de 2008.

"Produção da Pecuária Municipal", IBGE, 2000 a 2006. Disponível em http:// www.ibge.gov.br. Acesso em 20 de setembro de 2008. Pesquisa da Produção Agrícola Municipal, IBGE, 2000 a 2006. Disponível em http:// www.ibge.gov.br. Acesso em 20 de setembro de 2008. Kirby, R. K.; Laurance, W. S.; Albernaz, A. K.; Schroth, G.; Fearnside, F. M.; Bergen, S.; Venticinque, E. M.; Costa, C. (2006) "The future of deforestation in the Brazilian Amazon". Futures, Vol. 38: 432- 453. Lambin, E.F.; Geist, H.J.; Lepers, E. (2003) "Dynamics of land-use and land-cover change in tropical regions". Annual Review of Environmental Resources, Vol. 28, n 2: 205-246.

Lambin, E. F.; Turner, B. L.; Geist, H. J.; Agbola, S. B.; Angelsen, A.; Bruce, J. W.; Coomes, O. T.; Dirzo, R.; Fischer, G; Folke, C.; George, P. S.; Homewood, K.; Imbernon, J.; Leemans, R.; Li, X.; Moran, E. M.; Mortimore, M.; Ramakrishnan, P. S; Richards, J. F.; Skanes, H.; Steffen, W; Stone, G. D.; Svedin, U.; Veldkamp, T. A.; Vogel, C.; Xu, J. (2001) "The causes of land-use and land-cover change: moving beyond the myths". Global Environmental Change, Vol. 11:261-269. Lorena, R. B., Lambin, E. F. (2009) "The spatial dynamics of deforestation and agent use in the Amazon". Applied Geography, Vol. 29: 171-181.

Malhi, Y.; Roberts, J. T.; Betts, R. A. Killeen, T. J.; Li, W.; Nobre, C. A. (2008) "Climate change, deforestation, and the fate of the Amazon". Science, Vol. 319, $\mathrm{n}^{\circ}$ 5860: 169-173.

Margulis, S. (2003) "Causas do desmatamento da Amazônia brasileira”. Brasília: Banco Mundial.

Mello, N. A. (2006) "Políticas territoriais na Amazônia”. São Paulo: Annablume.

Morton, D. C.; DeFries, R. S.; Shimabukuro, Y. E.; Anderson, L. O.; Arai, E.; Espirito-Santo, F. B.;
Freitas, R.; Morisette, J. (2006) "Cropland expansion changes deforestation dynamics in the southern Brazilian Amazon". PNAS, vol. 103, n. 39: 1463714641.

Muchagata, M.; Brown, K. (2003) "Cows, colonists and trees: rethinking cattle and environmental degradation in Brazilian Amazonia". Agricultural Systems, Vol. 76: 797-816.

Nepstad, D.; Carvalho, G.; Barros, A. C.; Alencar, A.; Capobianco, J. P.; Bishop, J.; Moutinho, P.; Lefebvre, P.; Silva Jr., U. L.; Prins, E. (2001) "Road paving, fire regime feedbacks, and the future of Amazon forests". Forest Ecology and Management, Vol. 154, n' 3: 395-407.

Nepstad, D. C.; Stickler, C. M.; Almeida, O. T. (2006) "Globalization of the Amazon soy and beef industries: opportunities for conservation". Conservation Biology, Vol. 20, n. 6: 1595-1603.

Nepstad, D.; Stickler, C.; Soares-Filho, B.; Merry, F. (2008) "Interactions among Amazon land use, forests and climate: prospects for a near-term forest tipping point". Phil. Trans. R. Soc B.

Nepstad, D.; Soares-Filho, B. S.; Merry, F.; Lima, A.; Moutinho, P.; Carter, J.; Bowman, M.; Cattaneo, A.; Rodrigues, H.; Schwartzman, S.; McGrath, D. G.; Stickler, C. M.; Lubowski, R.; Piris-Cabezas, P.; Rivero, S.; Alencar, A.; Almeida, O.; Stella, O. (2009) "The end of deforestation in the Brazilian Amazon. Science, Vol. 326: 1350-1351.

Nogueira, E. M.; Fearnside, P. M.; Nelson, B. W.; França, M. B. (2007) "Wood density in forests of Brazil's 'arc of deforestation': implications for biomass and flux of carbon from land-use change in Amazonia". Forest Ecology and Management, Vol. 248: 119-135.

Ometto, J. P. H. B.; Nobre, A. D.; Rocha, H. R.; Artaxo, P.; Martinelli, L. (2005) "Amazonia and the modern carbon cycle: lessons learned". Oecologia, Vol. 143: 483-500.

Ostrom, E. (2009) "A general framework for analyzing sustentability of social-ecológical systems", Science, Vol 25: 419-421.

Pasquis, R.; Bouamrane, M. (2002) "Desflorestamento e impactos sobre a diversidade biológica: uma questão de escalas", in: S. H. Theodoro (org.) Conflitos e uso sustentável dos recursos natu- 
rais. Rio de Janeiro: Garamond.

Perz, S. G. (2003) "Social determinants and land use correlates of agricultural technology adoption in a forest frontier: a case study in the Brazilian Amazon". Human Ecology, Vol. 31, n 1: 133-165.

Pfaff, A. S. P. (1999) "What drives deforestation in the Brazilian Amazon? Evidence from satellite and socioeconomic data". Journal of Environmental Economics and Management, Vol. 37: 26-43.

Pimm, S. L.(1998) "The forest fragment classic". Nature, Vol. 393: 23-24.

Portela, R.; Rademacher, I. (2001) “Adynamic model of patterns of deforestation and their effect on the ability of the Brazilian Amazonia to provide ecosystem services". Ecological Modelling, Vol. 143: 115-146. Rayner, S.; Bretherton, F.; Buol, S.; Fosberg, M.; Grossman, W.; Houghton, R.; Lal, R.; Lee, J.; Lonergan, S.; Olson, J.; Rockwell, R.; Sage, C.; Imhoff, E. (1994) "A wiring diagram for the study of land use/cover change", in W. B. Meyer e B. L. TURNER II (org.) Changes in land use and land cover: a global perspective. Cambridge: Cambridge University Press.

Reis, E.; Margulis, S. (1991) "Perspectivas econômicas do desflorestamento da Amazônia". Texto para Discussão. Brasília: Instituto de Pesquisa Econômica Aplicada. Rivas, A.; Mota, J. A.; Machado, J. A. (orgs.) (2008) "Impacto virtuoso do Pólo Industrial de Manaus sobre a proteção da floresta amazônica: Discurso ou fato?" Manaus: Instituto Piatam.

Rivas, A. (1998) "The Manaus Free Trade Zone and deforestation in the State of Amazonas". Ph.D. Dissertation. Knoxville: The University of Tennessee. Sala, O. E.; Chapin, F. S.; Armesto, J. J.; Berlow, E.; Bloomfield, J. et al. (2000). "Biodiversity - global biodiversity scenarios for the year 2100". Science, ${ }^{\circ}$ 287:1770-1774.

Santana, R. F. (2008) “Os serviços ambientais da floresta e o manejo florestal sustentável: perspectivas para os agricultores familiares na área de influência da BR 163" in: CASTRO, E. (org.). Sociedade, território e conflitos: BR 163 em questão. Belém: NAEA.

Scheffer, M.; Carpenter, S.; Foley, J. A.; Folke, C.; Walker, B. (2001) "Catastrophic shifts in ecosystems". Nature, Vol. 413: 591-596.

Sayago, D.; Machado, L. (2004) "O pulo do grilo: o
Incra e a questão fundiária na Amazônia", in: D. Sayago,J. F. Tourrand E M. Bursztyn (org.) Amazônia: cenas e cenários. Brasília: Editora Universidade de Brasília.

Sawyer, D. R. (2007) "Amazon interventions and climate change", in: Crafting Policy in the Face of Politics: the Amazon in the Context of Brazil, workshop on Climate Change and the Fate of the Amazon, Oxford, mar. 20-23.

Simon, M. F.; Garagorry, F. L. (2005) "The expansion of agriculture in the Brazilian Amazon". Environmental Conservation, Vol. 32, $n^{\circ}$. 3: 203-212. Soares Filho, B. S.; Nepstad, D. C.; Curran, L.; Cerqueira, G. C.; Garcia, R. A.; Ramos, C. A.; Voll, E.; Mcdonald, A.; Lefebvre, P.; Schilezinger, P.; Mcgrath, D. (2005) "Cenários de desmatamento para a Amazônia". Estudos Avançados, Vol. 19, n. 54: 137-152.

S--teffen, W.; Sanderson, A.; Tyson, P. D.; Jäguer, J.; Matson, P. A.; Moore, B.; Oldfield, F.; Schelnhuber, H. J.; Turner, B. L.; Wasson, R. J. (2004) "Global change and the Earth system: a planet under pressure". New York, Springer.

Steward, C. (2007) "From colonization to environmental soy: a case study of environmental and socio-economic valuation in the Amazon soy frontier". Agriculture and Human Values, Vol. 24: 107-122.

Théry, H. (2005) "Situações da Amazônia no Brasil e no continente". Estudos Avançados, Vol. 19, n 53: 37-49.

Turner, B. L; Lambin, E. F.; Reenberg, A. (2007) “The emergence of land change science for global environmental change and sustainability".

PNAS, Vol. 104, n 52: 20667-20671.

Tourrand, J. F.; Valarié, P. ; Oliveira, J. R. D. (2007) "Monopoly amazonien". Cahiers Agricultures, Vol. 16, $\mathrm{n}^{\circ}$ 5: 423-427.

Vieira I. C. G., Proctor, J. (2007) "Mechanisms of plant regeneration during succession after shifting cultivation in eastern Amazonia". Plant Ecology, Vol. 192: 303-315.

Walker, R.; Perz, S.; Caldas, M.; Silva, L. (2002). "Land use and land cover change in forest frontiers: the role of household life cycles". International Regional Science Review, Vol. 25, n 2: 169-199.

Young, C.E.F. (1998) "Public policies and deforestation in the Brazilian Amazon". Planejamento e Políticas Públicas, Vol. 18: 201-222. 